\title{
A Water-productivity Framework for Understanding and Action
}

\author{
David Molden, Hammond Murray-Rust, R. Sakthivadivel \\ and Ian Makin \\ International Water Management Institute, Colombo, Sri Lanka
}

\begin{abstract}
Substantially increasing the productivity of water used in agriculture is essential to meet goals of food and environmental security. Achieving these increases requires research that spans scales of analysis and disciplines. In spite of its importance, we do not have a common conceptual framework and language to facilitate research and communication among stakeholders. The objective of this chapter is to propose a common conceptual framework for water productivity. In a broad sense, productivity of water is related to the value or benefit derived from the use of water. Definitions of water productivity differ based on the background of the researcher or stakeholder. For example, obtaining more kilograms per unit of transpiration is an important means of expressing productivity of water when the interest of analysis is crops. At the basin scale, obtaining more value from water used from irrigated and rain-fed crops, forests, fisheries, ecosystems and other uses is of importance. There are several interrelated definitions of water productivity that are important across scales and domains of analyses. We propose in this chapter a set of definitions for water productivity and show how these are related across scales.

As the analysis moves from individual plants to fields, farms, irrigation systems and water basins, different processes and means of analysis are important. Understanding how measures of water productivity scale up and scale down provides the key to how a group of people of diverse disciplines can work together on this topic. For example, crop scientists and breeders may focus on obtaining more mass per unit of transpiration, while planners and economists may consider policies to allocate water and land resources between different uses. To capture the full benefits of improved water productivity at farm level, it is necessary to integrate these with system- and basin-level changes. We provide a framework to show the interrelationship of the work of various disciplines.
\end{abstract}

\section{Introduction}

Increasing the productivity of water in agriculture will play a vital role in easing competition for scarce resources, prevention of environmental degradation and provision of food security. The argument for this statement is simple: by growing more food with less water, more water will be available for other natural and human uses (Molden and Rijsberman, 2001; Rijsberman, 2001).

Increasing productivity of water is partic- 
ularly important where water is a scarce resource. Physical scarcity, when there is no additional water in a river basin to develop for further use, is common in an increasing number of either dry or intensively developed basins (IWMI, 2000). In these cases, it is likely that increasingly less water will be available for agriculture and that, to sustain production, increases in water productivity will be necessary.

There are other important situations of scarcity. Economic scarcity describes a situation where there is water remaining in nature to be tapped for productive uses but there is extreme difficulty in developing the infrastructure for this water for economic, political or environmental reasons (IWMI, 2000).

A third common situation occurs when water and infrastructure are available and cultivation techniques are known and yet people do not have ready access to water. For example, a lack of water is often not the cause of a head-tail problem. As another example, poor people are excluded from infrastructural development and do not have equal access to the benefits available from a project. This management-induced scarcity has a variety of causes, including poor infrastructural development and maintenance but, often, it finds its roots in inappropriate or ill-functioning policies and institutions.

Water productivity is dependent on several factors, including crop genetic material, watermanagement practices, agronomic practices and the economic and policy incentives to produce. Corresponding to this, there are many people working in parallel on means to increase the productivity of water but the effort remains disjointed. Part of the reason is that we do not have a common conceptual framework for communicating about water productivity. The purpose of this chapter is to propose a conceptual framework to enable us to work and communicate better together.

After agreeing to work under the banner of 'more crop per drop' or 'producing more with less water' we immediately have to figure out what this means. These terms have different meanings for different people: more kilograms per unit of evapotranspiration (ET) for some, more production per unit of irrigation water delivered for others or more welfare per drop of water consumed in agriculture for others. In this framework, we accept that these are all important and relevant meanings, and our task is to sort out how these concepts relate to one another.

\section{More Crop per Drop: Which Crop and Which Drop?}

In a broad sense, productivity of water refers to the benefits derived from a use of water. The numerator then has a physical or economic term expressing the benefit. The denominator is a water term. The expression is most often given in terms of mass of produce, or monetary value, per unit of water. First, consider the denominator, water.

\section{Scale considerations}

Consideration of scales helps to untangle the 'which crop/which drop' problem. Water use and management in agriculture cross many scales: crops, fields, farms, delivery systems, basins, nations and the globe. Working with crops, we think of physiological processes: photosynthesis, nutrient uptake and water stress. At a field scale, processes of interest are different: nutrient application, waterconserving soil-tillage practices, bunding of rice-fields, etc. When water is distributed in an irrigation system, important processes include allocation, distribution, ${ }^{1}$ conflict resolution and drainage. At the basin scale, allocation and distribution are again important, but to a variety of uses and users of water. At the national and international scale, trade, prices and virtual water all have relevance. Processes between scales are inter-

\footnotetext{
${ }^{1}$ Allocation and distribution of irrigation water are primarily for irrigation farmers, but they are also to meet the demands of other domestic, industrial, livestock and fisheries uses.
} 
linked. For example, basin-scale allocation practices can set a constraint on how much water a farmer receives and the influence on farm water-management practices.

First, we surmise that issues of scale heavily influence concepts of water productivity. Second, we can differentiate scales of analysis by considering the processes important at each scale. We jump across scales when key processes of consideration change. Thirdly, actions at one scale often influence what happens at a different scale. Fourthly, the definition of water productivity found useful by people is dependent on the scale of analysis they are working at.

\section{Accounting for use and productivity of water}

Water accounting provides a means to generalize about water use across scales, and to understand the denominator of the water productivity better (Molden and Sakthivadivel, 1999). Water accounting can be applied at all scales of interest, and requires the definition of a domain bounded in three-dimensional space and time. For example, at the field scale, this could be from the top of the plant canopy to the bottom of the root zone, bounded by the edges of the field, over a growing season. The task in water accounting is to estimate the flows across the boundaries of the domain during the specified time period.

At the field scale, water enters the domain by rain, by subsurface flows and, when irrigation is available, through irrigation supplies. Water is depleted ${ }^{2}$ by the processes of growing plants: transpiration and evaporation. The remainder flows out of the domain as surface runoff or subsurface flows or is retained as soil-moisture storage. In estimating water productivity, we are interested in water inflows (rain plus irrigation, or just rainwater in rain-fed agriculture) and water depletion (evaporation and transpiration).

The water-accounting procedure classifies these inflow and outflow components into various water-accounting categories, as shown in Box 1.1. The main process of irrigation is the supply of water for crop transpiration to maintain a healthy environment for growth and production. Depletion by the intended processes of industrial (cooling, cleaning), domestic (washing, drinking) and agricultural uses (transpiration) is referred to as process depletion. The finger diagram in Fig. 1.1 shows the flow of water at the field scale. On the right side, water is depleted by the processes of transpiration and evaporation. In most cases, at field scale we cannot say that the outflow is depleted, as it may be recaptured somewhere downstream or by pumped groundwater use.

In rain-fed agriculture, the partitioning of evaporation and transpiration takes on special significance. Rockström et al. (Chapter 9, this volume), for example, argue that much of the evaporation can be transferred into crop transpiration, thus contributing to increased crop yield and increased water productivity.

Within an irrigation system we have the same inputs as in rain-fed agriculture - rainfall and surface and subsurface flows - plus artificial irrigation supplies. Irrigation infrastructure is primarily built to provide water for crop transpiration, but, in many irrigated areas, infrastructure also provides water for domestic and industrial uses and for fishing and livestock. In addition to the intended depletion by crop transpiration, water is also depleted by evaporation from weeds, trees, fallow land and water bodies. Drainage water is sometimes directed to sinks, such as oceans, saline water bodies or saline groundwater. Other outflows can be recaptured for use. However, disentangling these various processes demands the clear analytical framework of water accounting (see example in Fig. 1.2).

Like many intensively irrigated areas, most depletion is through crop ET. Other city and industrial-process depletion exists, but is small compared with crop ET. Non-crop vegetation contributes to non-process, but

${ }^{2}$ Depletion is when water is rendered unavailable for further use in the present hydrological cycle. This happens by evaporation, flows to sinks and incorporation into products. Water can also be considered depleted when it becomes too polluted for further use. 
Box 1.1. Water-accounting definitions.

Gross inflow is the total amount of water flowing into the water-balance domain from precipitation and from surface and subsurface sources.

Net inflow is the gross inflow plus any changes in storage.

Water depletion is a use or removal of water from a water basin that renders it unavailable for further use. Water depletion is a key concept for water accounting, as interest is focused mostly on the productivity and the derived benefits per unit of water depleted. It is extremely important to distinguish water depletion from water diverted to a service or use, as not all water diverted to a use is depleted. Water is depleted by four generic processes:

Evaporation: water is vaporized from surfaces or transpired by plants.

Flows to sinks: water flows into a sea, saline groundwater or other location where it is not readily or economically recovered for reuse.

Pollution: water quality gets degraded to an extent where it is unfit for certain uses.

Incorporation into a product: through an industrial or agricultural process, such as bottling water or incorporation of water into plant tissues.

Process consumption is that amount of water diverted and depleted to produce an intended product.

Non-process depletion occurs when water is depleted, but not by the process for which it was intended. Non-process depletion can be either beneficial or non-beneficial.

Committed water is that part of the outflow from the water-balance domain that is committed to meet other uses, such as downstream environmental requirements or downstream water rights.

Uncommitted outflow is water that is not depleted or committed and is therefore available for a use within the domain, but flows out of the domain due to lack of storage or sufficient operational measures. Uncommitted outflow can be classified as utilizable or non-utilizable. Outflow is utilizable if by improved management of existing facilities it could be used consumptively. Non-utilizable uncommitted outflow exists when the facilities are not sufficient to capture the otherwise utilizable outflow.

Available water is the net inflow minus both the amount of water set aside for committed uses and the non-utilizable uncommitted outflow. It represents the amount of water available for use at the basin, service or use levels. Available water includes process and non-process depletion plus utilizable outflows.

A closed basin is one where all available water is depleted.

An open basin is one where there is still some uncommitted utilizable outflow.

In a fully committed basin, there are no uncommitted outflows. All inflowing water is committed to various uses.

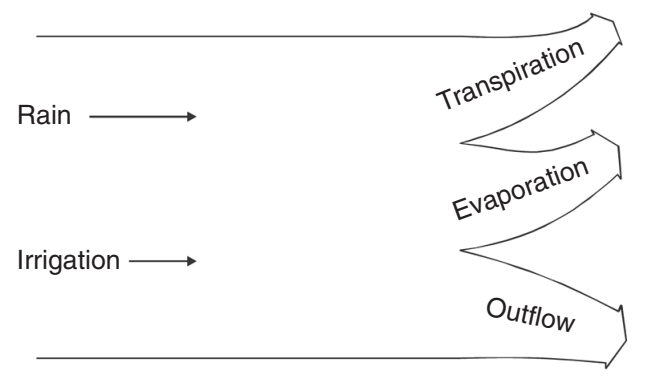

Fig. 1.1. Accounting for water use at field scale. Inflows are from rain and irrigation supplies. Water is depleted by crop transpiration and soil evaporation. The remaining liquid water flows out of the domain. beneficial, depletion. Irrigation directs flow to drains, which is not reused downstream and is therefore considered depleted. Some of the drainage flow is classified as committed in order to flush salts.

The benefits derived by depletion from trees or water bodies or even flows to saline water bodies can be appreciable. A strict focus on irrigation often leads us to forget that trees have aesthetic and economic value, that water bodies may be important for fisheries or that a sink may really be a wetland providing important ecological services. Unfortunately, some common terminology that we use, such as evaporation or drainage 'loss' or 'wastage', and even 'efficiency' in the way it is commonly defined (see Seckler et al., Chapter 3, 


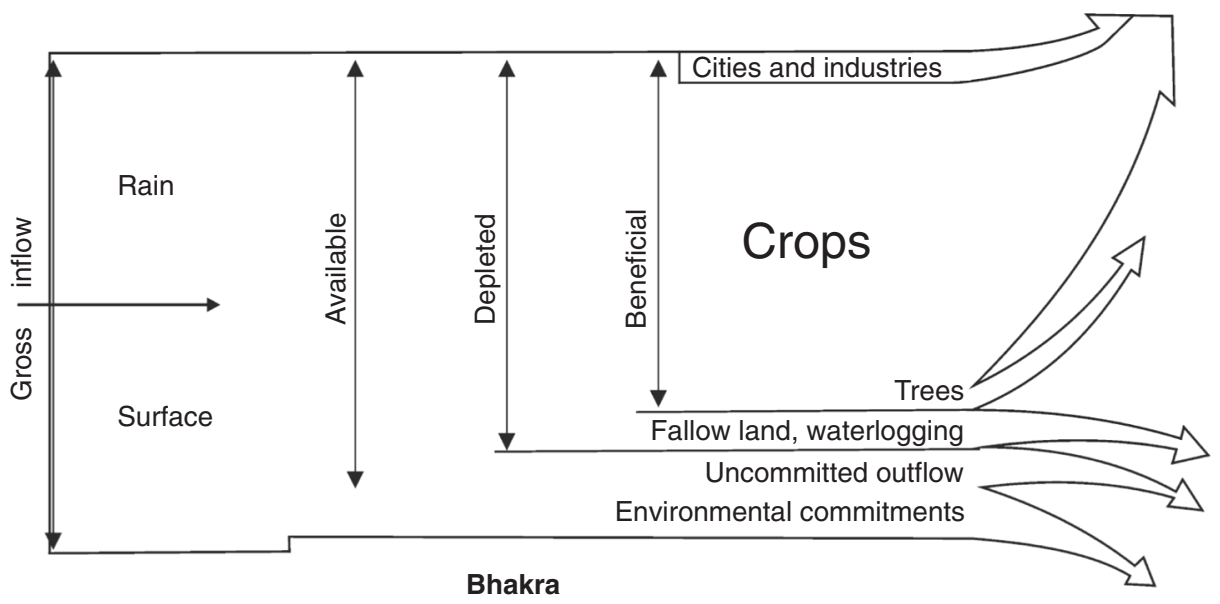

Fig. 1.2. Representation of the Bhakra irrigated area (Molden et al., 2001).

this volume), does not help us to decide what is beneficial and what is not. Figure 1.2 shows a finger diagram for water accounting at an irrigation-system scale, which from top to bottom on the right side shows:

- process depletion (by crops, cities, industries);

- non-process but beneficial depletion, such as evaporation by trees, wetlands within the system or fisheries;

- evaporative depletion of low or negative benefit, such as evaporation from fallow land or from waterlogged areas (that do not have important wetland values);

- flows that are directed by irrigation into sinks, such as seas or inland water bodies that do not add value, and which could have been used within the irrigation system or elsewhere - this is considered as water depleted by irrigation;

- uncommitted flows that are utilizable within the irrigation system or elsewhere;

- committed flows to meet environmental needs or legal or traditional rights of downstream users.
The domain of a basin can be defined by the catchment area of a river system to the salt-freshwater interface. ${ }^{3}$ In most cases, the only inflow is precipitation. ${ }^{4}$ A useful conceptual advance has been the partitioning of basin water into blue water, which contributes to river runoff, and green water, which evaporates or is transpired (Falkenmark, 2000). By concentrating only on blue water, we omit the benefits derived from the rain and chances of increasing productivity of overall supplies. We agree with this point of view and include precipitation in the water-accounting analysis. ${ }^{5}$ Land-use changes are a means of reallocating green water and altering the blue-green balance. Other concerns in water use and management relate to blue water. At the basin scale, other process uses - industrial and domestic, as well as depletion by ecosystems that provide valuable goods and services - are significant. ${ }^{6}$

We can generalize water accounting to other agricultural uses of water. If water is diverted and kept in ponds for fish, the surface evaporation from the pond is accounted for as water depleted by fisheries. If stream

\footnotetext{
${ }^{3}$ The analysis can be done constructively at sub-basin levels.

${ }^{4}$ Interbasin transfers or subsurface flows can, of course, be significant sources of inflow.

${ }^{5}$ Most irrigation-efficiency calculations start by subtracting effective rainfall.

${ }^{6}$ In many agricultural areas, the quantities of industrial and domestic depletion may be small, but the value derived from the use is significant.
} 
flows are maintained at minimum levels, restricting other uses, the amount of this water should also be considered as depleted by fisheries. ${ }^{7}$ In other cases, where fisheries arise because of the development of irrigation reservoirs, value is added to the water without additional depletion.

At the basin scale, outflows require special consideration. Some outflow is required to maintain an environmental balance - to flush out salts and pollutants, prevent salinewater intrusion and supply water and nutrients for coastal fisheries and ecosystems. Floodwater that cannot be captured by existing facilities is considered non-utilizable. The remaining water is considered utilizable for within-basin use. ${ }^{8}$

As we increase the scale of analysis, we tend to add more complexity. But, with increasing competition for water, the types of broad questions we ask are: How can we free water from irrigation for other uses? How can we reduce competition? How can we reduce environmental degradation? All of these require understanding of basin-scale processes. ${ }^{9}$ The solutions to these problems most often lie in actions taken at local scales - irrigated and rain-fed fields or within irrigation systems.

\section{Which drop?}

So, turning to the fundamental question in water productivity, which cubic metre do we refer to in the denominator of the equation?

Of fundamental concern in agriculture is how much production is derived per unit of crop transpiration. ${ }^{10}$ If we could increase the mass per unit of ET all over a basin, production would rise without an increase in water depleted by agriculture. Water productivity in terms of $\mathrm{kg}$ per unit of ET, then, seems to be the obvious target that we want to improve.
Water managers, however, tend to be more concerned with the water input. Farmers in rain-fed arid areas, for example, are extremely concerned with capturing and doing the most with limited rainfall. Where an additional supply is available as supplemental irrigation, maximizing the output from a small amount of additional irrigation supply is normally highly productive. For irrigation farmers and system managers, the water supply is the bread and butter of the business. Water supplies, whether rainfall, supplemental irrigation or full irrigation supplies, are candidates for the denominator.

Unfortunately, because scale and environmental factors influence the water supply term, it must be treated with extreme care. For example, where small amounts of irrigation are required in high-rainfall areas and the water-productivity formulation attributes all production to irrigation, productivity per irrigation supply can give high values and thus cannot be compared with areas with low rainfall. Further complicating the matter is that increases in productivity per irrigation supply may not 'scale up' in an intuitive manner (see Box 1.2). It is possible that increasing productivity per unit of supply at field scales may lead to lowering of productivity of supply at larger scales. If, for example, more efficient farm practices are used to grow more crops with the same supply for relatively low-valued uses, thereby reducing supplies to other farmers or uses (especially if they are higher-valued), the overall productivity of basin supplies may be reduced.

In all cases, production per unit of ET remains constant across scales. Increases in productivity of water per unit of ET would lead to increases in productivity of available water. At the farm level, the productivity of diverted water doubles from option I to option II in Box 1.2. Within the system, non-

\footnotetext{
7 Retaining minimum flows for fisheries or other ecosystem services could also be classified as an environmental commitment of water.

${ }^{8}$ Utilizable and non-utilizable water is dependent on the degree of infrastructural development. We could define a potentially utilizable flow, which could be depleted within the river basin.

9 And are also influenced by larger scales, such as trade and virtual water flows.

10 At scales above farm level, we tend to lump together evaporation and transpiration from agricultural fields as evapotranspiration (ET).
} 
Box 1.2. Production per diverted, depleted and available water.

The following schematic diagram represents two options for an irrigation system to deliver water to farms. In both cases, there are 100 units of production from each farm, 100 units of crop evapotranspiration from each farm and 50 units of rainfall on each farm. At the end of the system shown in the dotted line, 100 units are committed for downstream environmental and agricultural uses.

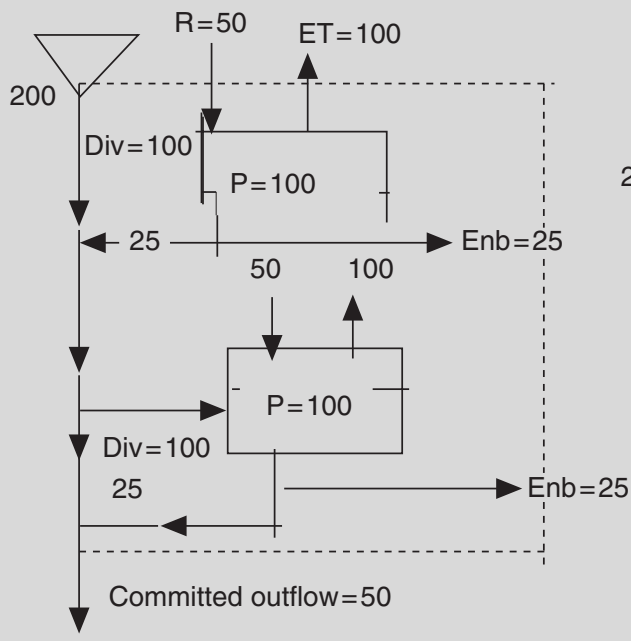

OPTION I

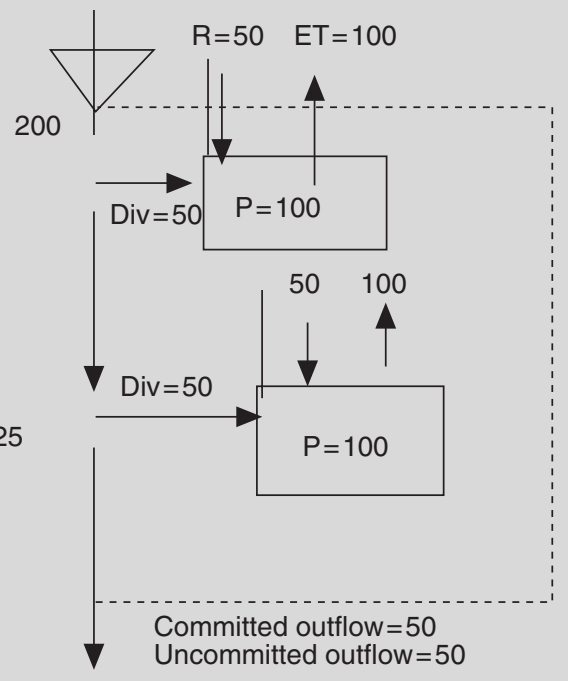

OPTION II

P, production; R, rain; Div, diverted water; ET, evapotranspiration; Enb, non-beneficial evaporation.

The strategies for delivering water are varied. In the first case, 100 units are delivered, while, in the second case, only 50 units are delivered to perfectly match crop evapotranspiration requirements. In the first case, 25 units return to the mainstream, because a waterlogged area has evaporated 25 units, while, in the second case, this waterlogging has been dried up, leaving more water in the mainstream. The following results are obtained:

\begin{tabular}{lrrrccccc}
\hline Option & Diverted & Rain & ET & Available & Production & P/ET & P/Diverted & P/Available \\
\hline I- farm & 100 & 50 & 100 & & 100 & 1.0 & 1.0 & \\
I- system & 200 & 100 & 200 & 250 & 200 & 1.0 & 1.0 & 0.80 \\
II - farm & 50 & 50 & 100 & & 100 & 1.0 & 2.0 & \\
II - system & 100 & 100 & 200 & 250 & 200 & 1.0 & 2.0 & 0.80 \\
\hline
\end{tabular}

beneficial evaporation is reduced in option II. But this does not lead to increases in productivity of water diverted from the reservoir or water available in the sub-basin. In the second case, the outflow is 100, 50 units more than the commitment of 50 units. In order to realize increased productivity of available supplies, the added 50 units (from decreased non-beneficial evaporation) would have to either be added to increased agricul- ture within the system or be made available to downstream uses (in which committed water would increase to 100). If an additional 50 units were consumed in agriculture, the productivity of available supplies would have increased to $250 / 250=1.0$.

Ideally, we should be able to specify an amount of water available for depletion within any domain. An unambiguous watermanagement goal would be to increase pro- 
ductivity of available supply. We can define 'available water' at any scale by subtracting the committed and non-utilizable outflow from the net inflow ${ }^{11}$ to the domain. (The available water is defined in the finger diagram shown in Fig. 1.3). Increasing the productivity of available water can be achieved by obtaining more per unit of ET and converting non-beneficial depletion to beneficial depletion (water savings) or by reallocating to higher-valued uses. Basin efficiency can be defined by the ratio of beneficial depletion to available water. While available water is an ideal term for water productivity and basin efficiency, it depends on a knowledge of committed flows, which are dependent on allocation rules, water rights and environmental requirements - whose values are unknown or absent in too many situations. We argue strongly for the concept of available supplies and for the need for better definition of rights and requirements within the basin, especially when water is becoming the scarce resource.

\section{Which crop?}

The next problem is the numerator of the water-productivity equation. Water productivity can be expressed in physical or economic terms as partial factor productivity (Table 1.1). Physical productivity is defined as the quantity of the product divided by the quantity of the input. Physical production is expressed in terms of mass $(\mathrm{kg})$, or even in monetary terms (\$), to compare different crops (Molden et al., 1998). Economic productivity uses valuation techniques to derive the value of water, income derived from water use and benefits derived from water or increased welfare. The valuation discussion requires much more emphasis than we can give here, and we refer readers to Chapter 2 by Barker et al. (this volume).

Let us focus the discussion on scale considerations. At the field and crop scale, farmers and researchers are typically interested in the mass of produce. For a farm enterprise, the interest of the farmer shifts to

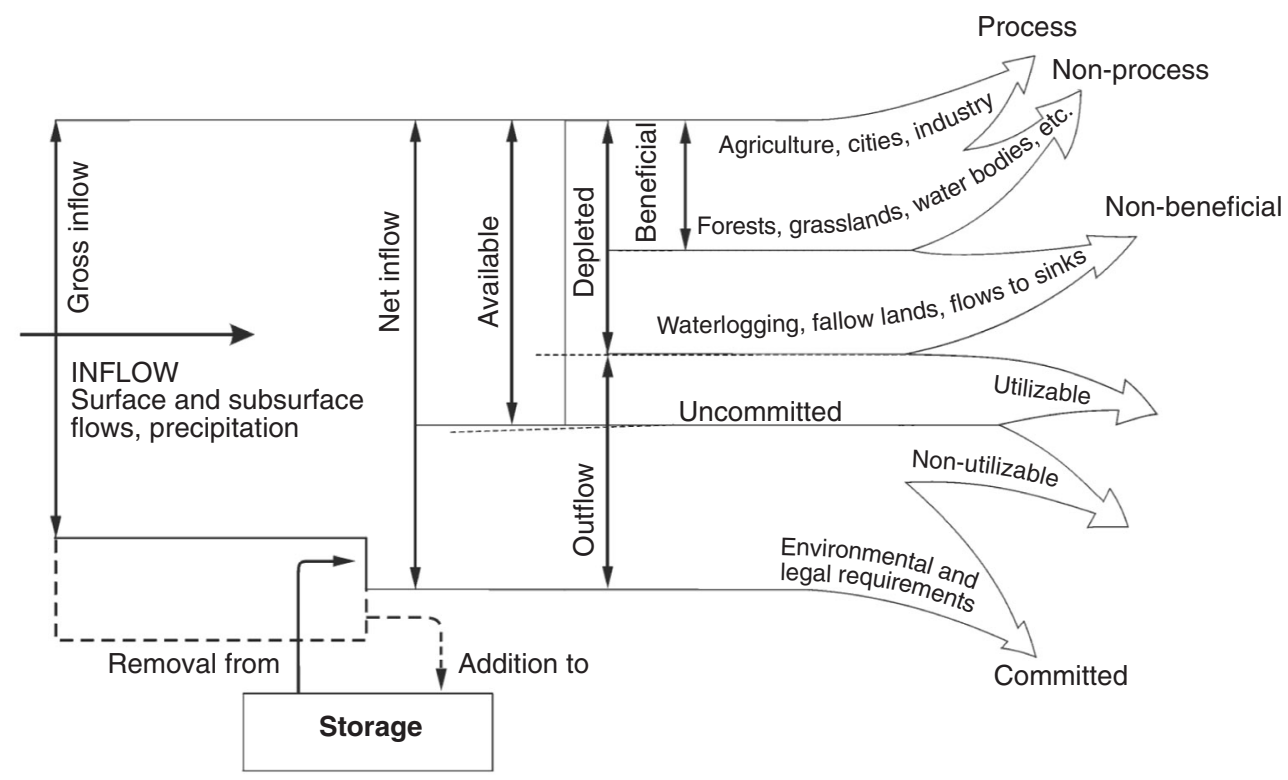

Fig. 1.3. Generalized water-accounting diagram, applicable to basin analysis and analysis at other scales.

\footnotetext{
${ }^{11}$ Net inflow is the water supply plus rain plus changes in storage. Where there is groundwater depletion, available water should be adjusted to reflect the long-term allowable amount of water that can be withdrawn from groundwater.
} 
Table 1.1. Scale considerations and water productivity.

\begin{tabular}{|c|c|c|c|c|c|}
\hline & Crop & Field & Farm & $\begin{array}{l}\text { Irrigation } \\
\text { system }\end{array}$ & Basin \\
\hline Processes & $\begin{array}{l}\text { Water and } \\
\text { nutrient uptake } \\
\text { and use, } \\
\text { photosynthesis, } \\
\text { etc. }\end{array}$ & $\begin{array}{l}\text { Tillage, } \\
\text { fertilizer } \\
\text { application, } \\
\text { mulching }\end{array}$ & $\begin{array}{l}\text { Distribution of } \\
\text { water to fields, } \\
\text { maximizing } \\
\text { income }\end{array}$ & $\begin{array}{l}\text { Distribution of } \\
\text { water to farms, } \\
\text { O\&M, fees, } \\
\text { drainage }\end{array}$ & $\begin{array}{l}\text { Allocation across } \\
\text { uses, regulation } \\
\text { of pollution }\end{array}$ \\
\hline $\begin{array}{l}\text { Scientific } \\
\text { interest }\end{array}$ & $\begin{array}{l}\text { Breeders, } \\
\text { plant } \\
\text { physiologists }\end{array}$ & $\begin{array}{l}\text { Soil scientists, } \\
\text { crop scientists }\end{array}$ & $\begin{array}{l}\text { Agricultural } \\
\text { engineers, } \\
\text { agricultural } \\
\text { economists }\end{array}$ & $\begin{array}{l}\text { Irrigation } \\
\text { engineers, } \\
\text { social } \\
\text { scientists }\end{array}$ & $\begin{array}{l}\text { Economists, } \\
\text { hydrologists, } \\
\text { engineers }\end{array}$ \\
\hline $\begin{array}{l}\text { Production } \\
\text { terms }\end{array}$ & $\mathrm{kg}$ & $\mathrm{kg}$ & $\mathrm{kg}, \$$ & $\mathrm{~kg}, \$$ & $\$$, value \\
\hline $\begin{array}{l}\text { Water terms } \\
\text { (cubic metres) }\end{array}$ & Transpiration & $\begin{array}{l}\text { Transpiration, } \\
\text { evaporation }\end{array}$ & $\begin{array}{l}\text { Evapotrans- } \\
\text { piration, } \\
\text { irrigation } \\
\text { supply }\end{array}$ & $\begin{array}{l}\text { Irrigation } \\
\text { deliveries, } \\
\text { depletion, } \\
\text { available } \\
\text { water }\end{array}$ & Available water \\
\hline
\end{tabular}

O\&M, operation and maintenance.

income derived or the provision of household food security. In water-scarce situations, though, farmers employ strategies to obtain more mass of production per unit of water supply, such as deficit irrigation (Perry and Narayanamurthy, 1998), supplemental irrigation (Oweis et al., 1999) or water-conservation practices (Rockström et al., Chapter 9, this volume). Water harvesting or employment of drought-resistant crops is also an important strategy for maintaining food security.

Irrigation-system managers may not be concerned about the production derived from irrigation-system water use, as their job tends to be delivery of supplies. However, policy makers, designers and researchers may be keenly interested in the economic output of irrigation systems. It is becoming increasingly apparent that the value of irrigation is not just derived from crops, but rather through the multiple uses of irrigation water (Bakker et al., 1999) or the inadvertent disbenefits produced when irrigation replaces other valuable goods and services. In the Hadejia-Jama'are floodplains in Nigeria, for example, it was found that the value of water in ecosystem services (fire- wood, fishing, recession agriculture and pastoralism) was found to be much higher than in irrigation (Barbier and Thompson, 1998, as quoted in IUCN, 2000).

At a basin scale, we would like to weigh the benefits of agricultural water uses against other uses. Production derived from industrial or agricultural processes tends to be relatively easier to give a monetary value to than domestic and environmental uses. In water-scarce situations, though, we are forced to consider these trade-offs. Many of these are difficult to quantify and are based on preferences of different members of society. As an example, there is a difficult trade-off between provision of water to poor people for household food security and provision of water for industries. The value of providing access to water for the poor for nutrition may be many times greater than the economic value of the produce, but this must be weighed against the jobs produced in an industrial sector. A first step is to work with stakeholders to highlight which uses are beneficial. Often, choices made are purely political, and the best that can be done is to illustrate and describe the tradeoffs at hand. 


\section{Achieving Sustainable Increases in the Productivity of Water}

In the early stages of river-basin development, we focused on developing and consuming more of the potentially available water by constructing more storage, diversion and distribution facilities. This essentially increases the productivity of potentially available supplies. When we focus on developed water supplies, there are two general pathways for increasing the productivity of water:

- Deplete more available water supply for beneficial purposes, by reducing nonbeneficial depletion and converting it to beneficial depletion. ${ }^{12}$

- Produce more output per unit of water depleted.

There are options to increase the productivity of water at each scale of interest, as described below.

\section{Opportunities for increasing water productivity at farm level}

Improvements in crop production can only be made at farm level. They result from the deliberate actions of individual farmers increasing production or the value of output with the same volume of available water or maintaining or increasing productivity using less water.

There are a number of different strategies by which farmers can improve waterproductivity values, described in detail in Box 1.3. Options include those related to plant physiology, which focus on making transpiration more efficient or productive, agronomic practices, which aim at reducing evaporation, and on-farm agricultural-engineering approaches, which aim at making water application more precise and more efficient.

In practice, many of these different strategies are mixed together because they are complementary. Most programmes to encourage farmers to improve on-farm water management involve combinations of plant physiol- ogy, agronomy and agricultural engineering, because there is a synergy involved in applying all three strategies simultaneously.

From the perspective of the Consultative Group on International Agricultural Research and its centers, however, it is important to distinguish carefully between the different strategies, because they require specialist skills that are significantly different. It also helps us in trying to distinguish the level at which we are assessing or measuring water productivity: even at farm level, we get different values of water productivity depending on whether we focus on the plant, the field or the whole farm. We need to know the potential for each component technology rather than the aggregate benefit from the different technologies when applied together.

\section{Farmer motivation to increase water productivity}

As discussed elsewhere in this chapter, the need to pay greater attention to water productivity is clearly seen when we look at the relationships between yield and water inputs (Fig. 1.4). With normal plant response functions to water, we always use water less productively in trying to maximize yields. From the so-called 'rational' perspective, if water is scarcer than land then under-irrigation is a logical strategy because it maximizes the scarcer resource.

However, water users are unlikely to use this set of relationships as a major motivation to use water more productively. Underirrigation is a strategy that can be highly beneficial if there is the prospect of rainfall that will result in big yield increases (e.g. wheat production in Pakistan and northwest India), but it is also a high-risk strategy if irrigation supplies fall below expectations.

\section{Improving productivity of water at irrigation- system and basin scales}

While increases in crop production take place on farms, there are a series of water-

12 In other words, by reducing waste or through real water savings. 
Box 1.3. Irrigation systems and basin-level strategies to increase water productivity.

Increasing the productivity per unit of water consumed:

- Improved water management - to provide better timing of supplies to reduce stress at critical cropgrowth stages, leading to increased yields or, by increasing the reliability of water supply so that farmers invest more in other agricultural inputs, leading to higher output per unit of water.

- Improving non-water inputs - in association with irrigation strategies that increase the yield per unit of water consumed; agronomic practices such as land preparation and fertilization can increase the return per unit of water.

Reducing non-beneficial depletion:

- Lessening of non-beneficial evaporation - by reducing evaporation from fallow land, by decreasing area of free water surfaces, decreasing non-beneficial or less-beneficial vegetation and controlling weeds.

- Reducing water flows to sinks - by interventions that reduce irrecoverable deep percolation and surface runoff.

- Minimizing salinization of return flows - by minimizing flows through saline soils or through saline groundwater to reduce pollution caused by the movement of salts into recoverable irrigation return flows.

- Shunting polluted water to sinks - to avoid the need to dilute with fresh water, saline or otherwise polluted water should be shunted directly to sinks.

- Reusing return flows.

Reallocating water among uses:

- Reallocating water from lower-value to higher-value uses - reallocation will generally not result in any direct water savings, but it can dramatically increase the economic productivity of water. Because downstream commitments may change, reallocation of water can have serious legal, equity and other social considerations that must be addressed.

Tapping uncommitted outflows:

- Improving management of existing facilities - to obtain more beneficial use from existing water supplies. A number of policy, design, management and institutional interventions may allow for an expansion of irrigated area, increased cropping intensity or increased yields within the service areas. Possible interventions are reducing delivery requirements by improved application efficiency, water pricing and improved allocation and distribution practices.

- Reusing return flows - through gravity and pump diversions to increase irrigated area.

- Adding storage facilities - so that more water is available for release during drier periods. Storage takes many forms, including reservoir impoundments, groundwater aquifers, small tanks and ponds on farmers' fields.

related actions at irrigation-system and basin scales that influence the basin-scale economic productivity of water. At these scales a series of diversion, distribution and reuse approaches are used either to reduce non-beneficial depletion or to direct water to higher-valued uses.

Within an irrigation system, strategies to reliably distribute water can facilitate the productive use by farmers. These are discussed in detail in the section below. Other strategies are aimed at reducing uncommitted outflows ${ }^{13}$ or at mixing water to control pollution loads. These are summarized in Box 1.3.

Basin strategies are typically directed at allocating water supplies and are aimed at shifting water from lower- to higher-valued uses within agriculture and between sectors. But, in addition, typically larger-scale infrastructure or groundwater can be used to promote the reuse of water. For example, the

${ }^{13}$ Not available for downstream use. 




Fig. 1.4. Theoretical relationship between yield and water productivity.

water-diversion structures along the Gediz River (IWMI and GDRS, 2000) or tank cascades (Sakthivadivel et al., 1997) provide a means of recapturing and redistributing water. Pollution control or mixing of highand low-quality water between sectors has an impact on water productivity. Strategies of land use can be used to increase water productivity.

\section{Linking farm-, irrigation-system- and basin- based water-management strategies to enhance water productivity}

To illustrate increases in water productivity, we focus the analysis initially on irrigation systems. A similar analysis could be done for water use by fisheries, rain-fed agriculture or agricultural livestock.

\section{Farm and irrigation-system interactions}

There are three possible scenarios that we need to explore to understand how we can maximize the productivity of water at system level.
FARM-LEVEL WATER AVAILABILITY REMAINS THE SAME If water availability for an individual farm remains the same, then there is no need for any changes at system or subsystem level to increase overall system-level water productivity. All gains will come from a set of uncoordinated actions from some or all of the farmers within the system. The probability is that individual farmers are responding to external factors that encourage them to increase productivity or profitability, independent of their water supply situation. An example of this could be a switch from grain for consumption to production of certified seeds: water consumption is identical but profitability is substantially higher.

ADOPTION OF IMPROVED FARM-LEVEL PRACTICES THAT REDUCE DEMAND FOR WATER Under this scenario there is a reduction in demand for water because of changed farm-level practices. Assuming that farmers cannot increase the area they irrigate, then adoption of new technologies or crops will reduce their overall demand for water. This happened in the Gediz basin in Turkey, where many farmers changed from cotton or grain crops to grapes. Not only are grapes for raisin pro- 
duction more profitable than other crops but they require less water. To take full advantage of this change in demand, system and subsystem canal operations had to change if the saved water was to be used productively elsewhere.

IMPOSITION OF REDUCED WATER DELIVERIES DUE TO REDUCED WATER AVAILABILITY The most common scenario is where there is less water available for agriculture at system or subsystem level. In this case, the pattern of water deliveries is changed and farmers must make specific responses at farm level that will lead to increases in water productivity.

There are several reasons why an individual may try to increase water productivity, and different choices bring with them completely different implications for making water more productive at different scales:

- Reduction in overall water supply.

- Imposed rationing from a higher level in an irrigation system (equivalent to a reduced water right).

- Declining groundwater table leading to reduced pumping rates.

- Change in incentives associated with farm-level water management.

- Imposed incentives to use less water (pricing, withdrawal of subsidies).

- Declining groundwater resources, which increase operational costs.

- Desires to increase farm-level profitability.

- Desire to get a better income from limited farm size by increasing production but without changing the basic cropping pattern.

- Decision to switch to higher-value crops to improve total farm income.

All of these reasons have one thing in common, which is that there have to be commensurate changes in farm-level management of land and water in order to improve water productivity. If such changes do not occur, then the likelihood is that individuals may reduce their cropped area, particularly if there are reductions in water supply, but do not significantly change their irrigation practices. The result will therefore be a decline in overall production without any significant change in water productivity. The yield per depth of water applied will remain the same on the fields that are irrigated, so that no water-productivity gains are made.

With the exception of the relatively rare case where changes at farm level have no impact on demand for water at farm level, we can assume that there is a direct interaction between farm-level and system- or subsystem-level management of water.

The direction of the interaction is an important one. In coping with responses to reductions in demand from individual farmers, the requirement at system and subsystem levels is to manage the additional water so that it can be used productively elsewhere. In cases of reduced water supply, some form of rationing is required that will force farmers to make changes in their farmlevel water-management practices. Because these are different management strategies, they are discussed separately.

\section{System-level responses to changes in farm- level water demand}

One peculiarity of assessing the productivity of water is that the values are highly dependent on the scale of analysis. A reduction in demand for water at farm level may result in a significant improvement in water productivity when measured at farm level but the values at subsystem level may remain unchanged unless there is a specific effort to utilize the water not used by an individual.

It is because of this peculiarity that, in most cases, we find that an individual working in isolation cannot save much water: it requires the action of others to ensure that the water not used by the individual is used for productive purposes.

Let us assume that an individual farmer refuses the full water entitlement because of the adoption of improved farm-level watermanagement practices. The refused water will then continue to flow down the canal past the farm gate. If there is no management response, then the refused water may flow to a sink with little or no benefit gained. To ensure that the refused water is used productively requires a clear set of management 
actions that ensure it is diverted to a productive use elsewhere.

This management action has to be by water users at subsystem level or by staff responsible for system-level operation. In either case, it requires direct communication between managers and water users to continually reassess demand refusal because the refusal is not the same as a permanent reduction in a water right.

This requires that the entire management system becomes demand-responsive and, if the demand response is flexible rather than permanently fixed, then it becomes a complex and extremely difficult task that is likely to stretch the management capacity of most irrigation systems. Most surface irrigation systems are not particularly demand-responsive. They may be able to make changes in long-term allocations through effective seasonal planning, but many find it difficult to be responsive to short-term and ephemeral changes in demand because these require flexible distribution rules.

In those cases where the demand is permanently reduced, it becomes easier to make appropriate changes in system- and subsystem-level rules and water allocations, because, once the change is made at the allocation level, the ensuing water distribution becomes a fixed process.

The situation is made even more complex where groundwater is a substantial source of water. Farmers may use less water by reducing their pumping but it is not always clear whether this results in water saving. That depends on how the aquifer is managed (either formally or informally) by water-user groups or through some form of imposed regulation.

Individual farmers have little incentive to voluntarily refuse water on a permanent basis unless there is some clear tangible benefit. Benefits could be reduced fee payments for water or water services, or deriving a benefit from reducing the adverse effects of getting too much water, such as waterlogging.

We can therefore conclude that, if waterproductivity increases at farm level result in individual demand refusals, it will be difficult to capture the unused water in a system- atic manner. As a result, we shall not see many system-level changes in water productivity, even though there may be apparent savings at the field and farm levels.

\section{Farm-level responses to changes in system- level water supplies}

The much more common scenario is that system-level water availability for irrigated agriculture will decline. This has two distinct differences from the previous discussion of demand-refusal conditions.

First, members of the staff responsible for system-level management have to make reductions in water deliveries. They have several different options open to them, detailed in Box 1.4 and shown graphically in Fig. 1.5. These options are to reduce the irrigated area, reduce discharge per unit area, impose rotational irrigation or shorten the total length of an irrigation season. These options can be combined to result in a series of different scenarios, each of which will have a distinct pattern of water delivery quite different from that which existed before the supply-based reductions were made.

From the perspective of the aim of increasing water productivity at farm level, the option of merely reducing the area irrigated but maintaining the same level of water supply per unit area is unlikely to result in improved water productivity. Individual water users have no external pressure to become more water-productive because there is no change in the relative balance of land and water resources for those farmers who get water.

All other scenarios provide water users with less water, and then they have to make the choice as to whether to adopt the type of measures discussed earlier that can result in improved water productivity at farm level or not. Because their water is now relatively scarcer than land, they can choose to become more water-productive if they so wish.

If water users get less water, then they have a direct incentive to be more waterproductive (per unit of irrigation supply) because the benefits are quickly tangible: they can maintain the same cropping inten- 
Box 1.4. Management responses to declining water availability at irrigation-system and subsystem levels.

- Reducing area to be irrigated but maintaining the same target discharges and length of irrigation season: this strategy maintains per-hectare water allocation for fewer farmers and is therefore unlikely to encourage adoption of measures to enhance water productivity.

- Reducing per-hectare water supply by reducing target discharges with continuous flow and maintaining total number of days of irrigation supply.

- Reducing per-hectare water supply by reducing target discharges with continuous flow and also reducing total number of days of irrigation supply.

- Reducing water allocation by reducing number of days of irrigation (rotation), maintaining target discharges and maintaining total number of days of irrigation supply.

- Reducing water allocation by reducing number of days of irrigation (rotation), maintaining target discharges and reducing total number of days of irrigation supply.

- Reducing water allocation by reducing number of days of irrigation (rotation), reducing target discharges and maintaining total number of days of irrigation supply.

- Reducing water allocation by reducing number of days of irrigation (rotation), reducing target discharges and reducing total number of days of irrigation supply.

sity as before by using less water per unit area. Whether this involves plant physiology, agronomy or agricultural engineering does not matter: all will mean that production is maintained even though water supplies are less.

\section{Strengthening farm-level and system-level linkages}

For water-productivity gains to be substantial and permanent, there must be effective linkages between what happens at farm level and what happens at system level. The choice of a particular technology or approach to farm-level water productivity can be made without regard to system-level management. Similarly, system-level management changes that may try to enhance water productivity can be made without knowledge of what is going on at farm level. However, both of these strategies will be suboptimal.

Let us take a simple example. The single most important innovation to improve the productivity of water has probably been the development and widespread adoption of short-season, high-yielding rice varieties. By reducing the length of life of the plants from, say, 5 to 3.5 months means that the number of days of irrigation drops from about 130 to 85 days without a substantial reduction of yield, if any. Yet the potential saving of some $35 \%$ of the total water requirement at field level can only be realized if system-level water issues are reduced by a similar amount.

The same argument applies for all of the technologies: if reduced demand is not matched by reduced supplies, no overall gains will be made at system level. Similarly, if imposed water reductions at system level merely result in fewer farmers getting water at the same level as before, then again there is no overall benefit.

The higher the level of analysis, the greater the importance of recognizing that water-productivity increases require actions not just by an individual water user but by those responsible for water management at system and basin levels.

\section{Linking water-management needs at basin level}

In the previous sections, we discussed interactions between water users and service providers. These two-way interactions are relatively easy to identify and describe. In contrast, linkages at basin level are much more difficult to identify and describe, for several reasons.

First, water demands for different sectors are not always quantified with the same pre- 


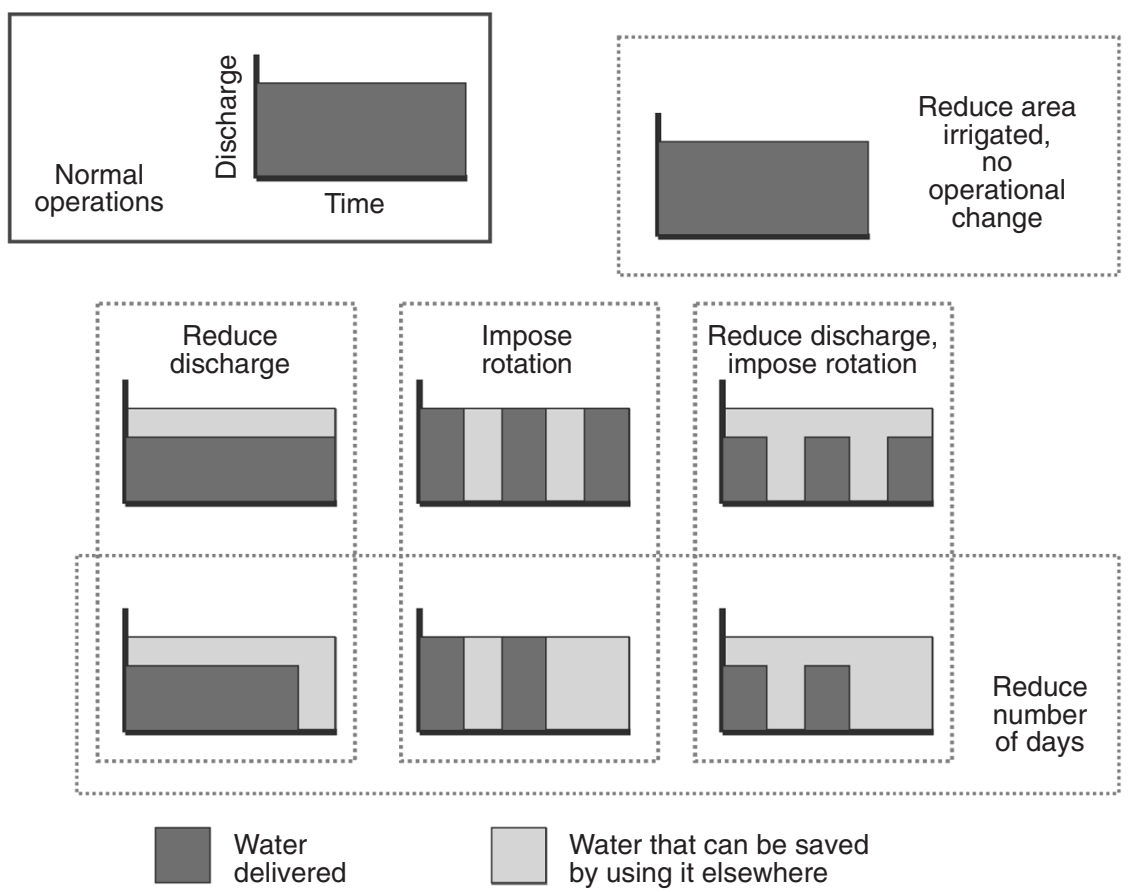

Fig. 1.5. Operational strategies at system or subsystem level that can be used to help save water.

cision. Diversion requirements of urban and industrial sectors are typically better defined than agricultural needs. Return flows are typically not well known and yet represent an important source of water for many people. Other sectors, in particular environmental needs, are less clearly defined. This makes the overall allocation process quite difficult, particularly when water rights do not change in response to changing demands and priorities.

The second complicating factor is that water allocations by sector have to account for multiple uses of the same quantum of water. For example, a single drop of water may serve hydropower, urban, fisheries and then agricultural needs before it is ultimately depleted. Water-management approaches may or may not take advantage of these possible synergies.

Institutional competition adds a third type of complexity. In many countries, some agencies or organizations are reluctant to collaborate with others. Organizations originally charged with large infrastructural construction seem particularly slow to respond to such concerns as environmental protection, water quality and recreation. While the establishment of basin-level management organizations can greatly assist in the process of water allocation between sectors, the actual management of water often rests with individual agencies that still act in a unilateral manner.

Fourthly, land-use decisions or water uses that do not constitute direct stream-flow diversions can have important water-use ramifications. More or less rain-fed agriculture influences movement of both water and salts. For example, in Western Australia, replacement of native forest cover with rain-fed crops resulted in additional recharge and a mobilization of salts (Turral, 1998). The National Land and Water Audit (2000) estimates that total dryland salinity in 2025 will affect 17.5 million ha, dwarfing the impacts of irrigation-induced salinity. Replacing grass with forests or forests with crops influences stream-flow hydrology. Groundwater use or rainwater harvesting may tap into 'blue water' that would other- 
wise flow into rivers and be available for downstream uses. ${ }^{14}$ It is not so obvious that these changes in use may affect other users and the overall productivity of basin water resources.

Clearly, at the basin scale, we are confronted with trade-offs. In closed and closing basins, actions taken on land and water in one part of the basin affect land and water use somewhere else, and in difficult-to-predict ways. These trade-offs are difficult to recognize, much less to quantify. Thus, valuing the productivity of water in its various uses and examining trade-offs require a basin perspective, especially in situations of intensive use, competition and scarcity.

\section{Conclusions and Recommendations}

The analysis of water productivity requires a clear understanding of the scale of analysis and the interaction between scales. We have developed expressions of water productivity pertinent to various scales of analysis and have shown the interrelation between scales, means of improving the productivity of water and various actors and disciplines involved in water productivity at various scales.

The productivity of water expressed as mass per unit of water transpired (or ET) is a basic measure of water productivity, valid at any scale. Production per unit of water diverted is an important measure for management, but is not comparable across scales or readily comparable across locations and does not necessarily lead to improvements in the productivity of water diverted at larger scales. Neither measure - productivity per unit of ET or water diverted - provides adequate information about the desires of society to grow more food with less water, to transfer water out of other uses or to use more environmentally sound practices. For this, basin measures related to the amount of water available for agriculture are required.

We have shown that improving the productivity of water in agriculture requires the integrated efforts of many players. For researchers, this does not fall in the domain of one group of specialists but rather requires the efforts of breeders, naturalresource-management specialists, physical scientists, sociologists and more. In practice, it depends on using the synergistic efforts of farmers and water-resource managers at different scales.

While preparing this chapter, three types of issues emerged.

1. We have to be very careful in identifying the scale at which we measure water productivity. The issue of the scale of analysis is fundamental to the improvement of water productivity. As we move from one scale to another, the potential utility of a cubic metre of water changes. Measuring productivity at plant level is relatively simple: the cubic metre refers to the volume of water transpired. But at the basin scale a cubic metre may have many potential uses, each of which values the same water quite differently. Research is required to determine what water productivity really means at different scales within the same basin.

2. There is a need to better understand interactions between scales. Interventions made on a local farm or irrigation scale do not necessarily lead to direct increases in productivity at larger scales, nor do they necessarily free water for higher-value uses, such as cities and, increasingly, the environment. Much more effort is required to understand what impact interventions at one scale have on different scales.

3. We need to examine more closely the tradeoffs between different uses of water. One consequence of basin-level analysis of water, particularly in water-scarce basins, is the recognition that each use of water in the basin has impacts on other uses and users. Within agriculture, these trade-offs will involve analysis of water use by fisheries, forests, livestock and field crops. Analysing each water use independently often leads to false conclusions because of these interactions.

Improving water productivity in agriculture will contribute in a major way to the many water problems with which we are

\footnotetext{
${ }^{14}$ In contrast, converting green-water evaporation to transpiration may not affect other uses of water.
} 
confronted. At present, our combined knowledge is probably sufficient to solve most water-resource problems. What we have not yet done is to combine our knowledge to the maximum effect to address these problems.

\section{References}

Bakker, M., Barker, R., Meinzen-Dick, R. and Konradsen, F. (eds) (1999) Multiple Uses of Water in Irrigated Areas: a Case Study from Sri Lanka. SWIM Paper 8, International Water Management Institute, Colombo, Sri Lanka.

Barbier, E.B. and Thompson, J.R. (1998) The value of water: floodplain versus large-scale irrigation benefits in Northern Nigeria. Ambio 27(6), 434-440.

Falkenmark, M. (2000) Competing freshwater and ecological services in the river basin perspective: an expanded conceptual framework. Water International 25(2), 172-177.

IUCN (World Conservation Union) (2000) Vision for Water and Nature: a World Strategy for Conservation and Sustainable Management of Water Resources in the 21st Century. Gland, Switzerland.

IWMI (International Water Management Institute) (2000) World water supply and demand 1995 to 2025 (draft). International Water Management Institute, Colombo, Sri Lanka. www.cgiar.org/iwmi/ pubs/WWVisn/WWSDOpen.htm.

IWMI and GDRS (General Directorate of Rural Services) (2000) Irrigation in the Basin Context: the Gediz River Basin Study, Turkey. International Water Management Institute, Colombo, Sri Lanka.

Molden, D.J. and Rijsberman, F. (2001) Assuring water for food and environmental security. Paper presented at the CGIAR Mid-Term Meeting 2001 in Durban, South Africa, on 26 May. Duplicated.

Molden, D.J. and Sakthivadivel, R. (1999) Water accounting to assess uses and productivity of water. Water Resources Development 155(1 \& 2), 55-71.

Molden, D.J., Sakthivadivel, R.C., Perry, J., de Fraiture, C. and Kloezen, W.H. (1998) Indicators for Comparing Performance of Irrigated Agricultural Systems. Research Report 20, International Irrigation Management Institute, Colombo, Sri Lanka.

Molden, D.J., Sakthivadivel, R. and Habib, Z. (2001) Basin Use and Productivity of Water: Examples from South Asia. Research Report 49, International Water Management Institute, Colombo, Sri Lanka.

National Land and Water Audit (2000) Australian Dryland Salinity Assessment 2000. Canberra, Australia.

Oweis, T., Hachum, A. and Kijne, J. (1999) Water Harvesting and Supplemental Irrigation for Improved Water Use Efficiency in Dry Areas. SWIM Paper 7, International Water Management Institute, Colombo, Sri Lanka.

Perry, C.J. and Narayanamurthy, S.G. (1998) Farmer Response to Rationed and Uncertain Irrigation Supplies. Research Report 24, International Irrigation Management Institute, Colombo, Sri Lanka.

Rijsberman, F. (2001) Can the CGIAR solve the world water crisis? Paper presented at the CGIAR MidTerm Meeting 2001 in Durban, South Africa, on 26 May.

Sakthivadivel, R., Fernando, N. and Brewer, J.D. (1997) Rehabilitation Planning for Small Tanks in Cascades: a Methodology Based on Rapid Assessment. Research Report 13, International Irrigation Management Institute, Colombo, Sri Lanka.

Turral, H. (1998) Hydro Logic? Reform in Water Resources Management in Developed Countries with Major Agricultural Water Use: Lessons for Developing Countries. Overseas Development Institute, London, UK. 